\title{
High pretreatment plasma D-dimer predicts poor survival of colorectal cancer: insight from a meta-analysis of observational studies
}

\author{
Shao-Long Lu ${ }^{1}$, Zhi-Hua Ye ${ }^{1}$, Tong Ling ${ }^{1}$, Si-Yuan Liang ${ }^{1}$, Hui Li ${ }^{1}$, Xiao-Zhun Tang ${ }^{2}$, \\ Yan-Song $\mathrm{Xu}^{2}$ and Wei-Zhong Tang ${ }^{1}$ \\ ${ }^{1}$ Department of Colorectal Surgery, First Affiliated Hospital of Guangxi Medical University, Nanning, Guangxi Zhuang \\ Autonomous Region 530021, P. R. China \\ ${ }^{2}$ Department of Emergency, First Affiliated Hospital of Guangxi Medical University, Nanning, Guangxi Zhuang Autonomous \\ Region 530021, P. R. China
}

Correspondence to: Wei-Zhong Tang, email: tangweizhong0771@163.com

Keywords: D-dimer, prognosis, colorectal cancer

Received: June 16, 2017 Accepted: August 26, $2017 \quad$ Published: September 15, 2017

Copyright: Lu et al. This is an open-access article distributed under the terms of the Creative Commons Attribution License 3.0 (CC BY 3.0 ), which permits unrestricted use, distribution, and reproduction in any medium, provided the original author and source are credited.

\section{ABSTRACT}

D-dimer, one of the canonical markers of hypercoagulability, was reported to be a potential prognostic marker of colorectal cancer. However, an inconsistent conclusion existed in several published studies. Thus, we performed this metaanalysis to provide a comprehensive insight into the prognostic role for pretreatment D-dimer in colorectal cancer. Six databases (English: Pubmed, Embase and Web of Science; Chinese: CNKI, Wangfang and VIP) were utilized for the literature retrieval. Hazard ratio (HR) was pooled by Stata 12.0. A total of fifteen studies ( 2283 cases) corresponded to this meta-analysis and provided available data to evaluate the prognostic role of D-dimer for colorectal cancer. The pooled HR reached 2.167 (95\%. CI (confidence interval): 1.672-2.809, $P<0.001$ ) utilizing random effect model due to obvious heterogeneity among the included studies $\left(I^{2}: 73.3 \% ; P<0.001\right)$. To explore the heterogeneity among the studies, we conducted a sensitivity analysis and found a heterogeneous study. After removing it, the heterogeneity reduced substantially ( $\mathrm{I}^{2}$ : $0 \% ; P=0.549)$ and we obtained a more convincing result by fixed effect model $(H R=$ $2.143,95 \% C I=1.922-2.390, P<0.001,14$ studies with 2179 cases). In summary, high pretreatment plasma D-dimer predicts poor survival of colorectal cancer based on the current evidence. Further prospective researches are necessary to confirm the role of D-dimer in colorectal cancer.

\section{INTRODUCTION}

Colorectal cancer, as a common malignancy in the world, has accounted for the second and third of cancer related death in male and female respectively [1]. Though the patients with early colorectal cancer reach satisfied survival, the advanced ones always own poor survival attributed to unresectable primary tumor, resistance and recurrence [2-4]. Thus, it is necessary to search for efficacious markers to assess the prognosis of colorectal cancer, especially in advanced stage.

Increasing evidence has observed aberrant blood coagulation in the patients with cancers $[5,6]$. As an established risk factor of blood hypercoagulability, the tumor cells release various cytokines to activate coagulation $[7,8]$. D-dimer is a canonical marker of hypercoagulability and a common approach to evaluate the hypercoagulable state in clinical practice [9]. Aberrant D-dimer has been detected in various cancers including colorectal cancer and several studies showed elevated D-dimer was correlated with poor survival of colorectal cancer $[10,11]$. However, the inconsistent conclusion of pretreatment plasma D-dimer in colorectal cancer could not be ignored $[12,13]$. Up to now, whether the pretreatment plasma D-dimer could be used for a predictive biomarker for the prognosis of colorectal cancer is controversial 
based on current evidence. Therefore, a comprehensive meta-analysis to combine the published studies is essential in order to reach a more convincing conclusion.

\section{RESULTS}

\section{Literature retrieval}

A total of 713 records were identified from the initial search. Thirty-eight studies were analyzed with fulltext after excluding the reduplicated or irrelevant studies. Finally, fifteen studies were used for this comprehensive meta-analysis and detailed information of eligible articles were presented in Table 1 [10-24]. The flow diagram of this meta-analysis was provided in Figure 1.

\section{Association of elevated D-dimer and overall survival}

Fifteen eligible studies (a total of 2283 cases) which ranged from 2001 to 2017 included patients with colorectal cancer of TNM stage I-IV (Dukes stage A-D) that were accepted surgery and/or chemotherapy. Among the fifteen studies, twelve studies showed positive results of the relationships between elevated D-dimer and overall survival of colorectal cancer, and three studies obtained negative results. The combined HR of the fifteen eligible studies was 2.167 (95\% CI $=1.672-2.809, P<0.001$, Figure 2) by a random effect model due to obvious heterogeneity $\left(\mathrm{I}^{2}=73.3 \%, P<0.001\right)$.

Subsequently, the sensitivity analysis was employed to investigate the source of heterogeneity among the eligible studies. We observed that the pooled result varied dramatically after removing a certain article (Kimberly et al.) with distinct cut off value of D-dimer (Figure $3)$. Therefore, we deleted it and gained a homogeneous pooled result (14 studies with 2179 cases) with fixed effect model which was more convincing $(\mathrm{HR}=2.143,95 \% \mathrm{CI}$ $=1.922-2.390, P<0.001$; heterogeneity test: $\mathrm{I}^{2}: 0 \%, P$ : 0.549 , Figure 4)

\section{Subgroup analysis}

We conducted subgroup analysis according to three factors (region, treatment and statistical method for survival). The results were presented in Table 2. Both in the studies of Asia and non- Asia, high D-dimer could predict poor survival of colorectal cancer, especially in Asia population (Figure 5). Likewise, we gained consist significant results in the rest two subgroup analyses (Figures 6-7).

\section{Publication bias}

The funnel plot was presented in Figure 8 and no obvious was observed from the Egger's test $(P=0.292)$.

\section{DISCUSSION}

Colorectal cancer, as a malignant neoplasm with high incidence worldwide, owns unsatisfied survival in advanced stage due to metastasis, recurrence and resistance of chemotherapy $[1,25,26]$. Thus, an efficacious biomarker to predict the prognosis of colorectal cancer is necessary, thereby providing potential target for treatment. D-dimer is a clinically common

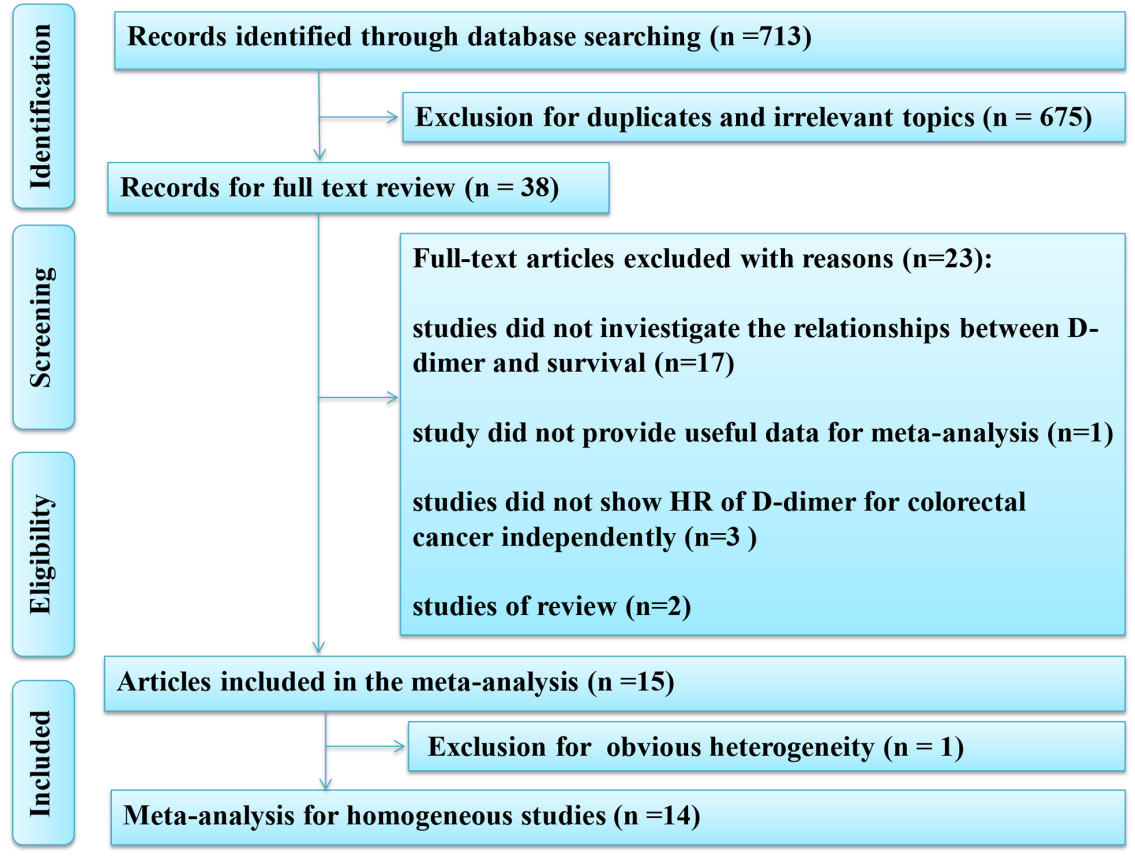

Figure 1: Flow diagram of the meta-analysis. 
Table 1: The characteristics of the included studies

\begin{tabular}{|c|c|c|c|c|c|c|c|c|c|c|c|c|c|c|c|c|}
\hline Author & Year & Region & $\begin{array}{c}\text { Number } \\
\text { of patients }\end{array}$ & Age (years) & $\begin{array}{c}\text { Gender } \\
\text { (Male/ } \\
\text { Female) }\end{array}$ & $\begin{array}{l}\text { Tumor } \\
\text { location } \\
\text { (Colon/ } \\
\text { Rectum) }\end{array}$ & $\begin{array}{l}\text { TNM } \\
\text { stage }\end{array}$ & $\begin{array}{l}\text { Dukes } \\
\text { stage }\end{array}$ & Treatment & Cut-off value & $\begin{array}{c}\text { Follow-up } \\
\text { (months) }\end{array}$ & $\begin{array}{l}\text { Survival } \\
\text { analysis }\end{array}$ & HR & LL & UL & $\begin{array}{l}\text { NOS } \\
\text { score }\end{array}$ \\
\hline Suee Lee & 2017 & $\begin{array}{l}\text { South } \\
\text { Korea }\end{array}$ & 170 & $28-84\left(63^{b}\right)$ & $107 / 63$ & $110 / 60$ & I-IV & $\mathrm{NA}$ & Surgery & $1.4 \mathrm{mg} / \mathrm{L}$ & $>60$ & survival curve & 5.890 & 2.050 & 16.950 & 7 \\
\hline Hong Tingting & 2017 & China & 505 & $27-93\left(62.97^{\circ}\right)$ & $265 / 240$ & NA & I-IIIC & $\mathrm{NA}$ & Surgery & $0.216 \mathrm{mg} / \mathrm{L}$ & $43^{*}$ & multivariate & 1.720 & 0.700 & 4.230 & 8 \\
\hline Kemal TekeGin & 2016 & Turkey & 134 & $31-84\left(62.5^{b}\right)$ & $84 / 50$ & $94 / 40$ & I-IV & $\mathrm{NA}$ & Surgery or RFA & $0.96 \mathrm{mg} / \mathrm{L}$ & $18^{*}$ & multivariate & 1.873 & 1.032 & 3.494 & 8 \\
\hline Zhao Shuangshuang & 2016 & China & 62 & $35-84$ & $41 / 21$ & $38 / 24$ & $\mathrm{NA}$ & $\mathrm{NA}$ & Chemotherapy & $0.8 \mathrm{mg} / \mathrm{L}$ & 50 & multivariate & 2.38 & 1.082 & 5.235 & 8 \\
\hline Xu Haifei & 2015 & China & 60 & $37-86\left(61.3^{3}\right)$ & $32 / 28$ & $26 / 34$ & $\mathrm{NA}$ & A-D & Surgery & $0.3 \mathrm{mg} / \mathrm{L}$ & $52.5^{*}$ & multivariate & 2.557 & 1.003 & 6.516 & 8 \\
\hline Ehsan Motavaf & 2014 & Denmark & 166 & $38-94 \quad\left(69^{b}\right)$ & $103 / 63$ & $87 / 79$ & $\mathrm{NA}$ & $\mathrm{NA}$ & Surgery & $0.3 \mathrm{mg} / \mathrm{L}$ & $60^{*}$ & multivariate & 2.200 & 1.100 & 4.800 & 8 \\
\hline Zhu Liming & 2014 & China & 74 & $31-74\left(55.5^{b}\right)$ & $40 / 34$ & $44 / 30$ & $\mathrm{NA}$ & $\mathrm{NA}$ & Chemotherapy & $1.9 \mathrm{mg} / \mathrm{L}$ & $18.4^{*}$ & multivariate & 3.520 & 1.280 & 9.670 & 8 \\
\hline Xue Liying & 2014 & China & 40 & $\begin{aligned}> & =70(n=22) ; \\
& <70(\mathrm{n}=18)\end{aligned}$ & $26 / 14$ & $21 / 19$ & $\mathrm{NA}$ & $\mathrm{NA}$ & Chemotherapy & $5.0 \mathrm{mg} / \mathrm{L}$ & 36 & multivariate & 4.386 & 2.101 & 9.174 & 8 \\
\hline Wang Junfeng & 2013 & China & 341 & $23-90$ & $178 / 163$ & $188 / 153$ & I-III & $\mathrm{NA}$ & Surgery & $0.5 \mathrm{mg} / \mathrm{L}$ & $64^{*}$ & multivariate & 1.829 & 0.110 & 7.893 & 8 \\
\hline Manabu Yamamoto & 2012 & Japan & 42 & $\begin{aligned}> & =70(n=30) ; \\
& <70(n=2)\end{aligned}$ & $26 / 16$ & $25 / 17$ & $\mathrm{NA}$ & $\mathrm{NA}$ & Chemotherapy & $1.0 \mathrm{mg} / \mathrm{L}$ & $14.1^{*}$ & multivariate & 3.749 & 1.127 & 18.160 & 8 \\
\hline Gurkan Tellioglu & 2012 & America & 242 & $63^{a}$ & $81 / 161$ & NA & $\mathrm{NA}$ & $\mathrm{NA}$ & RFA & $1.0 \mathrm{mg} / \mathrm{L}$ & $22^{*}$ & multivariate & 2.090 & 1.840 & 2.360 & 8 \\
\hline Corrado Pedrazzani & 2010 & Italy & 199 & $26-94\left(67.7^{b}\right)$ & $118 / 81$ & $141 / 58$ & $\mathrm{NA}$ & $\mathrm{NA}$ & Surgery & $0.25 \mathrm{mg} / \mathrm{L}$ & 60 & survival curve & 1.500 & 0.860 & 2.610 & 8 \\
\hline Kilic M & 2007 & Turkey & 51 & $29-80\left(60.9^{9}\right)$ & $34 / 17$ & NR & $\mathrm{NA}$ & A-D & Surgery & $0.375 \mathrm{mg} / \mathrm{L}$ & $20^{*}$ & survival curve & 2.970 & 1.180 & 7.480 & 6 \\
\hline Kimberly Blackwell & 2004 & America & 104 & $23-85\left(61^{\mathrm{b}}\right)$ & $43 / 57$ & NA & $\mathrm{NA}$ & $\mathrm{NA}$ & Chemotherapy & $0.001332 \mathrm{mg} / \mathrm{L}$ & $>25$ & multivariate & 1.180 & 1.020 & 1.371 & 8 \\
\hline Masatoshi Oya & 2001 & Japan & 93 & $27-84\left(62.7^{2}\right)$ & $62 / 31$ & $51 / 42$ & I-III & $\mathrm{NA}$ & Surgery & $0.85 \mathrm{mg} / \mathrm{L}$ & $54.7 *$ & multivariate & 1.874 & 1.001 & 3.497 & 7 \\
\hline
\end{tabular}

a: mean age; b: median age; NA: not available; RFA: radio frequency ablation; *: median of follow-up; NOS: Newcastle-Ottawa Scale

Table 2: Subgroup analysis of the meta-analysis

\begin{tabular}{lllllllll}
\hline Subgroup & $\begin{array}{l}\text { Number of } \\
\text { studies }\end{array}$ & $\begin{array}{l}\text { Pooled } \\
\text { HR }\end{array}$ & $\mathbf{9 5 \%}$ CI & & $\boldsymbol{P}$ & Medol & $\mathbf{I}^{2}$ & $\boldsymbol{P}$ \\
\hline Region & & & & & & & & \\
Asia & 9 & 2.745 & 2.030 & 3.711 & $<0.001$ & Fixed effect & $0.0 \%$ & 0.565 \\
non-Asia & 5 & 2.066 & 1.838 & 2.321 & $<0.001$ & Fixed effect & $0.0 \%$ & 0.730 \\
$\begin{array}{l}\text { Treatment } \\
\text { Surgery }\end{array}$ & 9 & 2.055 & 1.587 & 2.660 & $<0.001$ & Fixed effect & $0.0 \%$ & 0.620 \\
non-Surgery & 5 & 2.163 & 1.919 & 2.439 & $<0.001$ & Fixed effect & $25.6 \%$ & 0.251 \\
Analysis of survival & & & & & & & & \\
Multivariate & 11 & 2.140 & 1.912 & 2.394 & $<0.001$ & Fixed effect & $0.0 \%$ & 0.802 \\
Survival curve & 3 & 2.692 & 1.210 & 5.992 & 0.015 & Random effect & $64.1 \%$ & 0.062 \\
\hline
\end{tabular}

HR: hazard ratio.

marker of activation of coagulation system. Increasing evidence showed that malignant neoplasm could promote the activation of coagulation, and elevated D-dimer was detected in several cancers which correlated to the prognosis, including in lung cancer, gastric cancer, and colorectal cancer [27-29]. Ma et al. have demonstrated high D-dimer predicted worse survival in lung cancer by a meta-analysis [30]. However, regarding colorectal cancer, the prognostic value of $\mathrm{D}$-dimer was contentious based on the published studies.

In this current meta-analysis, we performed an integration of the current evidence (14 studies including 2179 cases) and provided a more stable and convincing result. The results of this current meta-analysis indicate high pretreatment plasma $\mathrm{D}$-dimer could predict poor survival of colorectal cancer (HR $=2.143,95 \%$ CI: 1.922 2.390). Subgroup analysis according to region, treatment and statistical method for survival, also showed consistent results: D-dimer could act as a predictive factor of survival both in the patients undergoing surgery, and the ones with metastasis received chemotherapy. The heterogeneity test and publication bias test all demonstrated the conclusion of the meta-analysis was stable.

In terms of the role of D-dimer in prognosis of patients with colorectal cancer, this following evidence may support our conclusion. At the genetic level, Vossen et al. confirmed that prothrombotic factor polymorphisms increased risk of colorectal cancer [31]. Yu et al. established that hypercoagulability owned a causal link to cancer-related genes (K-ras and p53) in colorectal cancer [32]. Meanwhile, the studies by Kemal et al., Wang et al. and Blackwell et al. revealed elevated D-dimer was associated with advanced $T$ stage, positive lymph node metastasis, metastasis and cell differentiation [14-16]. Due to the close relationships between D-dimer and unfavorable clinicopathologic characteristics of colorectal cancer, the association between D-dimer and poor survival of colorectal cancer was understandable. Moreover, several studies clarified that plasma D-dimer of patents with colorectal cancer reduced obviously after surgery or 


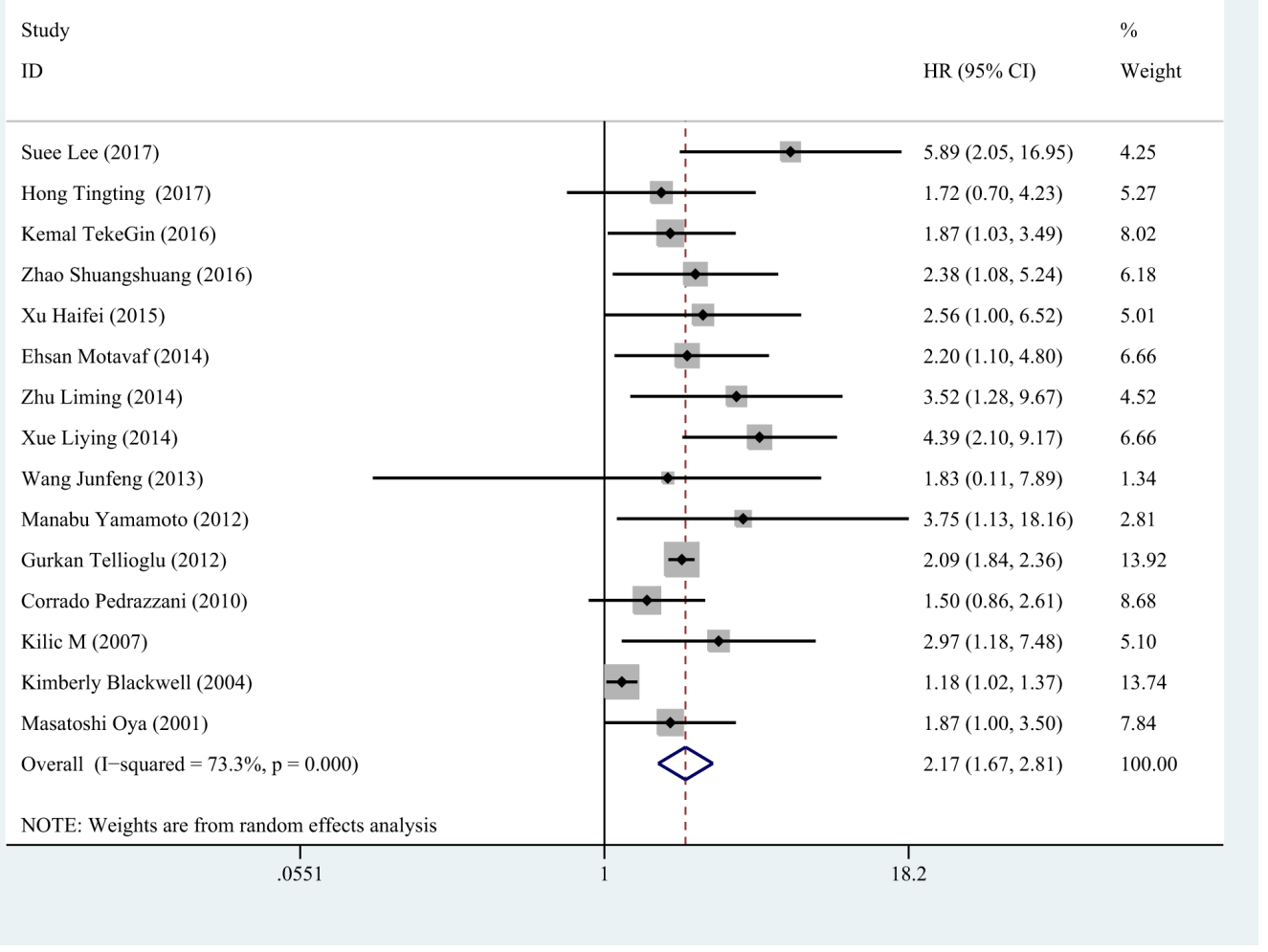

Figure 2: The forest plot of all included studies. The pooled HR of all included fourteen studies was 2.167 (95\% CI: 1.672-2.809, $P<0.001$, random effect model due to obvious heterogeneity: $\mathrm{I}^{2}=73.3 \%$ ).

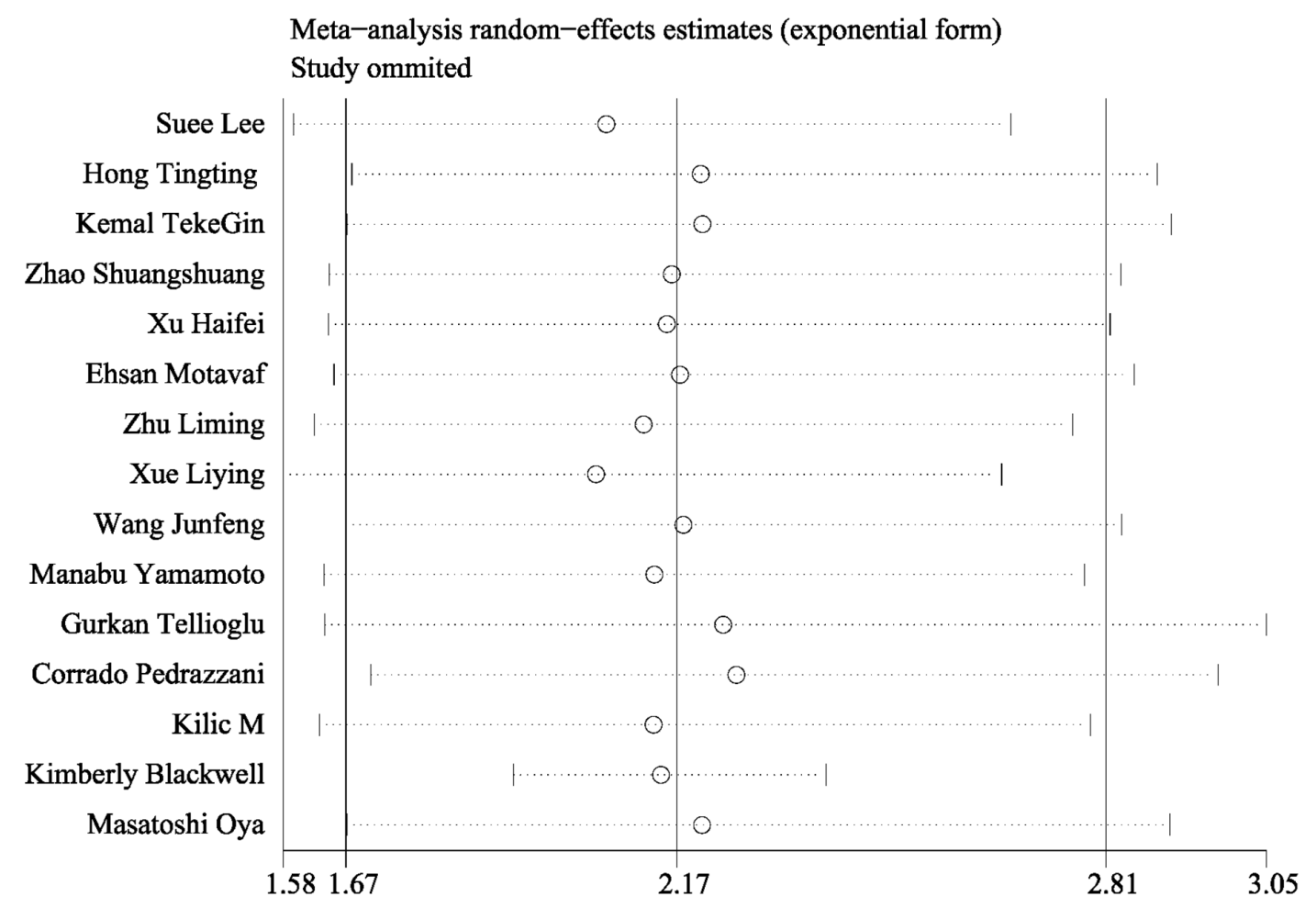

Figure 3: The sensitivity analysis of all included studies. The combined result varied dramatically after excluding the study reported by Kimberly Blcakwell. 


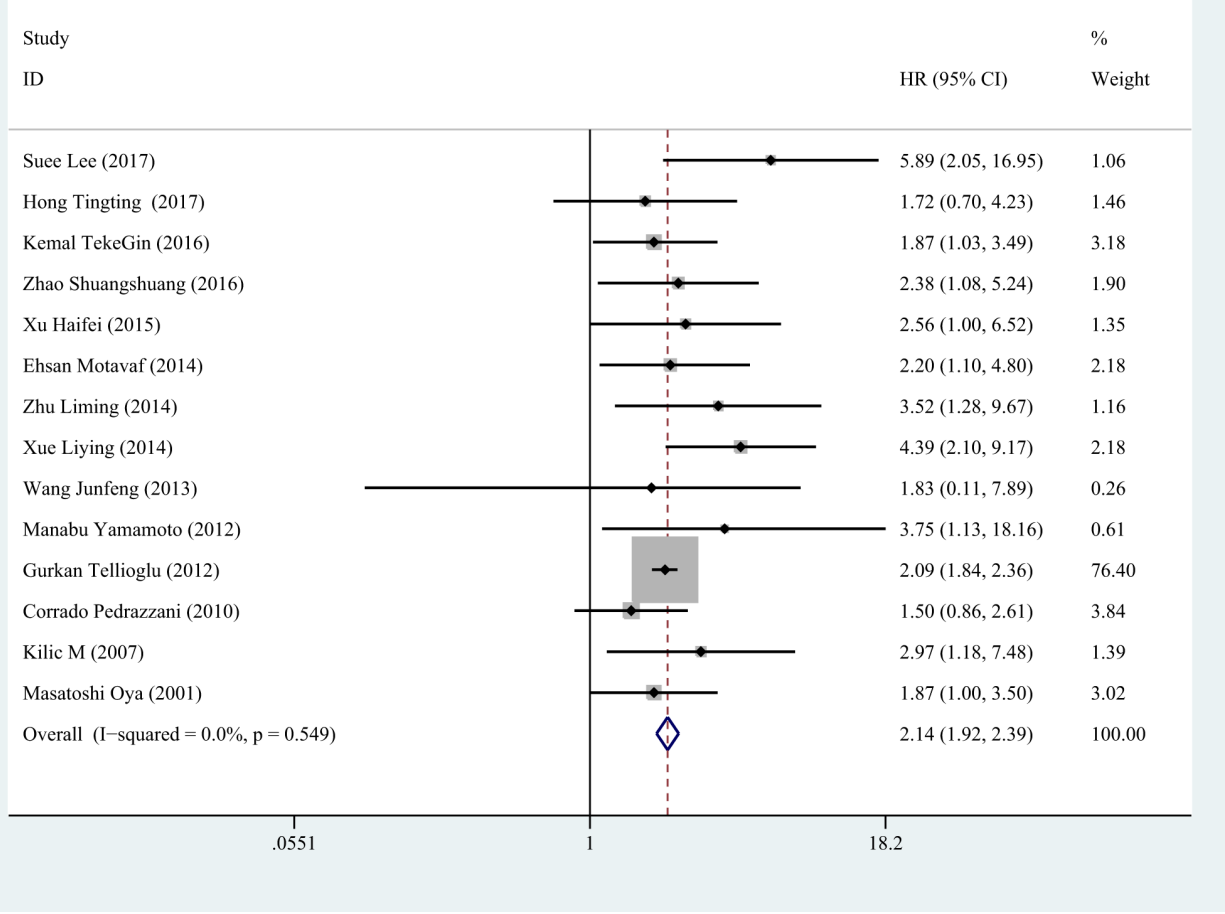

Figure 4: The forest plot of fourteen homogeneous studies. The included homogeneous studies showed significant pooled HR of the prognostic value of D-dimer in colorectal cancer ( $\mathrm{HR}=2.143,95 \%$ CI: $1.922-2.390, P<0.001$, fixed effect model due acceptable heterogeneity: $\mathrm{I}^{2}=0 \%$ ).

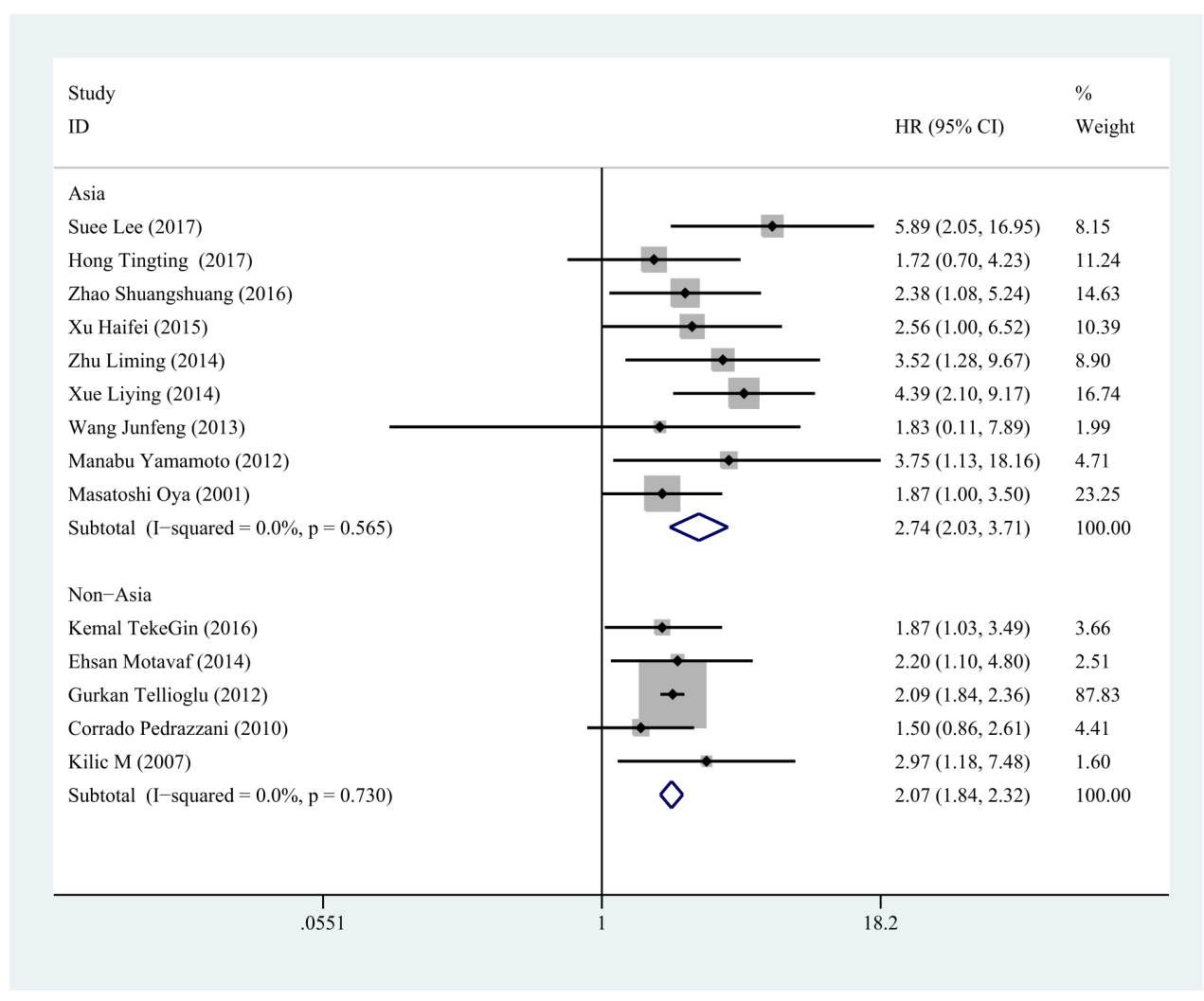

Figure 5: Subgroup analysis for region. In Asia, the HR of D-dimer was 2.745 ( $95 \% \mathrm{CI}$ : $2.030-3.711, P<0.001$, fixed effect model). In non- Asia, a similar result was observed ( $\mathrm{HR}=2.066,95 \% \mathrm{CI}: 1.838-2.321, P<0.001$, fixed effect model). 


\begin{tabular}{l} 
Study \\
ID \\
\hline Surgery \\
Suee Lee (2017) \\
Hong Tingting (2017) \\
Kemal TekeGin (2016) \\
Xu Haifei (2015) \\
Ehsan Motavaf (2014) \\
Wang Junfeng (2013) \\
Corrado Pedrazzani (2010) \\
Kilic M (2007) \\
Masatoshi Oya (2001) \\
Subtotal (I-squared $=0.0 \%, \mathrm{p}=0.620)$ \\
Non-surgery
\end{tabular}

Figure 6: Subgroup analysis for treatment. In the patients undergoing surgery, the HR of D-dimer was 2.055 (95\% CI: 1.587-2.660, $P<0.001$, fixed effect model) and a consistent result was gained in the patients received chemotherapy $(\mathrm{HR}=2.163,95 \% \mathrm{CI}: 1.919-2.439$, $P<0.001$, fixed effect model).

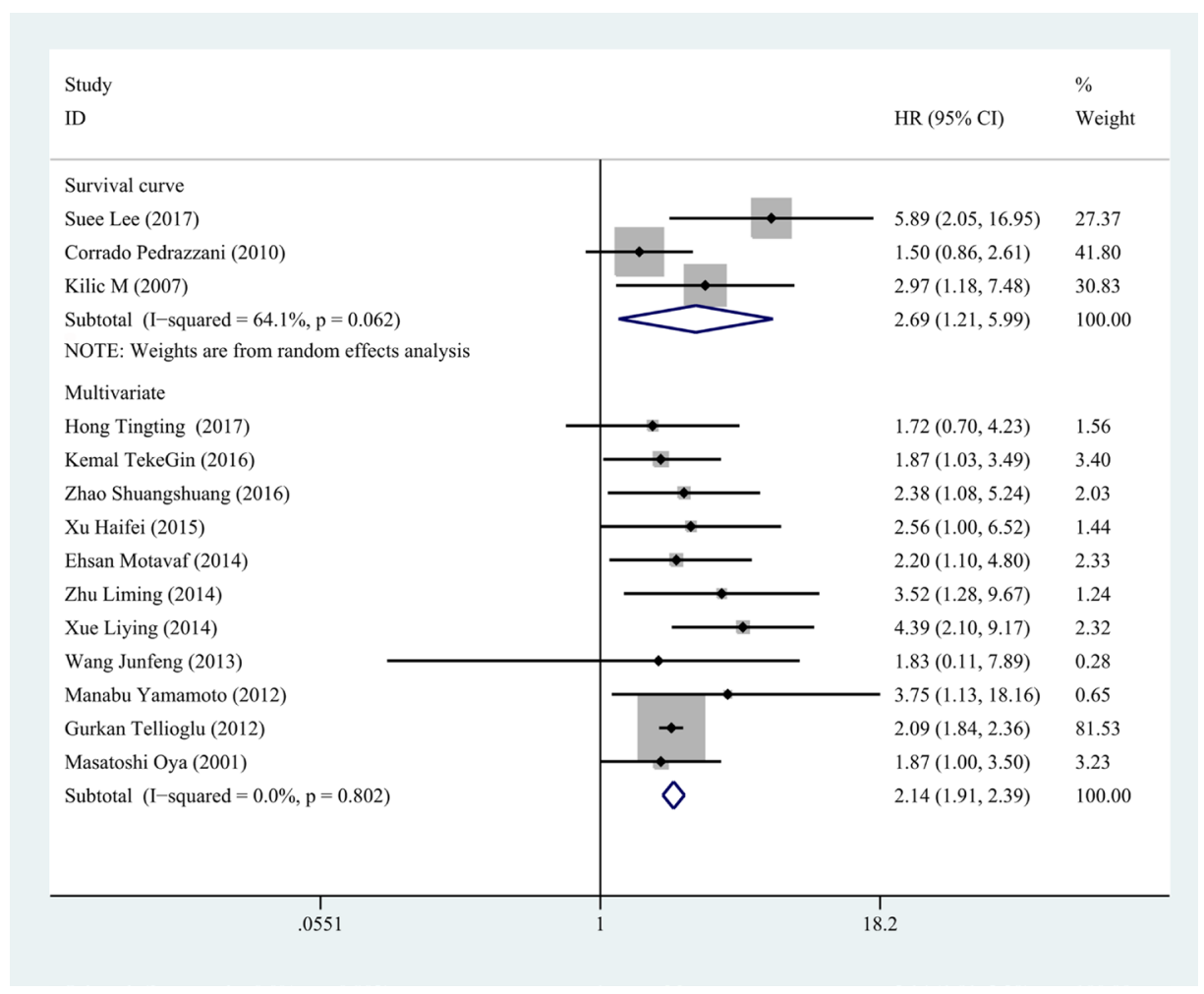

Figure 7: Subgroup analysis for the method of survival analysis. The pooled HR from multivariate analysis was 2.140 (95\% CI: 1.912-2.394, $P<0.001$, fixed effect model) and pooled HR from survival curve was 2.692 (95\% CI: 1.210-5.992, $P=0.016$, random effect model). 
chemotherapy which indicated the higher tumor burden the higher plasma D-dimer [33-35]. Therefore, the prognostic role of plasma D-dimer in pretreatment colorectal cancer was acceptable based on the aforementioned evidence.

Furthermore, the use of D-dimer for the prediction of survival in colorectal cancer should be based on a clear definition of high D-dimer because of the confounding factors, such as race, detection method, etc.

As $\mathrm{Yu}$ et al. reported, we could not assess D-dimer status exactly according to normal reference range in the patients with cancers [36]. Thus, tumor-specific D-dimer reference range should be further investigated with more epidemiological studies and provides a useful standard for clinical practice.

Though our study provided a more convincing conclusion that D-dimer could act as a predictive biomarker of prognosis for colorectal cancer, some inevitable limitations should be discussed: 1) several included studies did not show the TNM stage or Dukes stages of colorectal cancer and it may cause the heterogeneity among the included patients and affect the application of this meta-analysis; 2) a study [29] with negative result was excluded due to unavailable data for meta-analysis which may lead to an exaggerated positive conclusion; 3) limited sample size of several included articles may give a underpowered HR, and thereby impact the pooled HR; 4) studies only in English or Chinese were included which may lead to incomplete evidence collection. Thus, a prospective study with a large sample to confirm the conclusion of this meta-analysis and cover the above limitations is indispensable.

Collectively, our meta-analysis showed primary comprehensive insight into the significant role in prognosis of plasma D-dimer in pretreatment colorectal cancer and D-dimer maybe a potential target for the treatment of colorectal cancer. The patients with colorectal cancer may benefit from anticoagulation interaction. Moreover, further prospective investigations with large sample size are demanded to validate the role of D-dimer in colorectal cancer.

\section{MATERIALS AND METHODS}

\section{Literature retrieval}

In the present comprehensive meta-analysis, we searched six databases to collect the evidence, containing three databases in English (PubMed, Web of Science and Embase) and three databases in Chinese (database of China National Knowledge Infrastructure (CNKI), VIP and WanFang). The terms for retrieval were: 1) "D dimer" or D-dimer or "D-dimer fibrin" or "D-dimer fragments" or "fibrin fragment D1 dimer"; 2) colorectal or colon or rectal or bowel; 3) cancer or carcinoma or adenocarcinoma or tumour or tumor or malignanc* or neoplas*. The literature retrieval of this current meta-analysis was updated to June 12, 2017.

\section{Selection criteria}

The eligible standards of the screen for the initial identified records were that 1) colorectal cancer should be pathological diagnosis, 2) detection of D-dimer was conducted in pretreatment colorectal cancer, 3) exploration of the relationships between D-dimer and prognosis of patients with colorectal cancer, and the data of prognosis was available directly or indirectly, 4) English or Chinese article, and 5) the recent study or study with a largest sample size will be included if the population is repetitive.

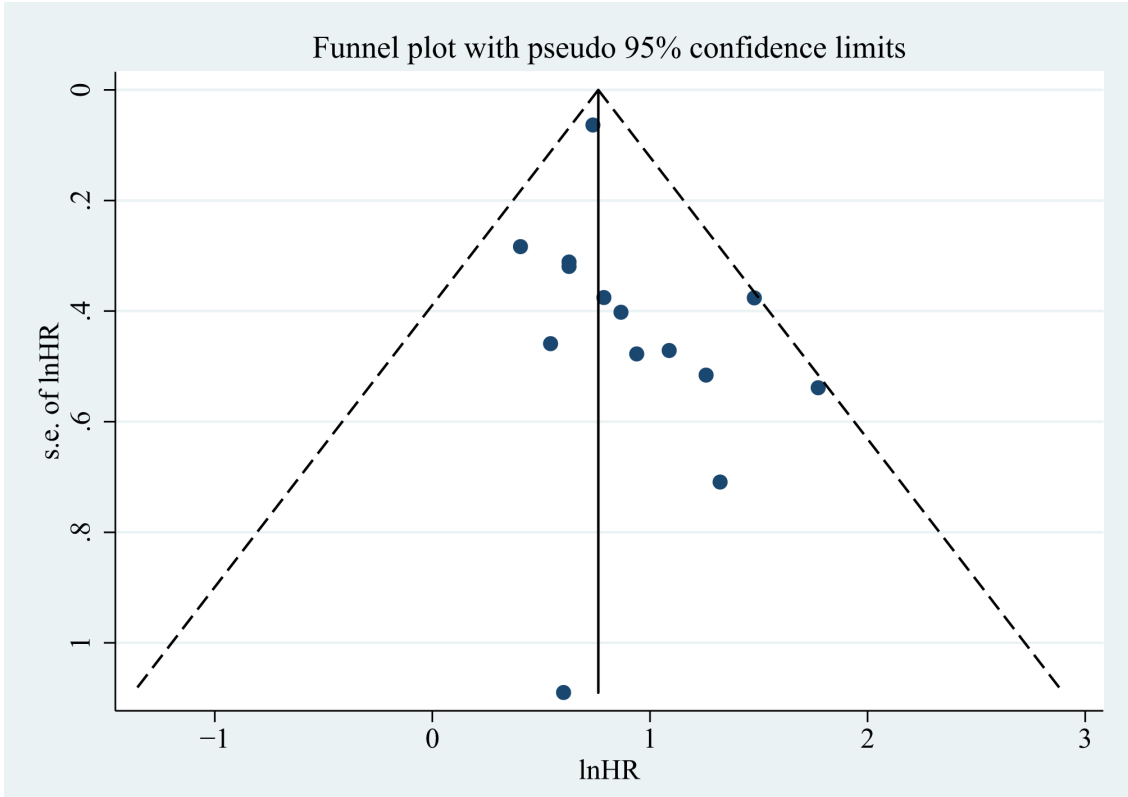

Figure 8: The funnel plot of included studies. No obvious publication bias was observed (Egger's test: $P=0.153$ ). 
The exclusion criterias for the primary studies included 1) reviews, letters, conference data, and case reports, 2) an overlap among articles or duplicate data, 3) the use of animals, 4) unavailable HR.and $95 \%$ CI of the study

\section{Data extraction}

Two authors screened the initial records independently and the final decision would be obtained by the third one if inconsistent conclusion existed. Information of the first authors, publication period, region, sample size, stage of colorectal cancer, cut off value, treatment, and HR were extracted. Moreover, we fellow a preferable order for HR extraction: HR (from multivariate analysis) $>$ HR (from univariate analysis) $>$ HR (extracted from Kaplan-Meier survival curve).

\section{Quality evaluation}

Newcastle-Ottawa Scale (NOS) was employed to estimate the quality of each eligible studies [37]. A certain study is evaluated from 3 sections for the included cohort: selection, comparability and evaluation for outcome. The quality of a certain article was determined by stars summation of the above 3 sources and the study with star $\geq 5$ is acceptable.

\section{Statistical analysis}

The data combination of this meta-analysis was carried out by Stata 12.0. The prognostic value of plasma D-dimer in pretreatment colorectal cancer patients was evaluated via combined HR together with corresponding $95 \%$ CI. $Q$ test as well as $\mathrm{I}^{2}$ statistic was utilized to estimate the heterogeneity of the pooled articles. In the meta-analysis, a model of fixed-effect was selected if heterogeneity of pooled studies was acceptable $(P>0.1$ and $\mathrm{I}^{2}<50 \%$ ) [38]. If not, we used a model of random-effect to combine the HR. The publication bias was examined by Egger's test and $P<0.05$ indicates statistical significance.

\section{CONFLICTS OF INTEREST}

The Authors declare that there is no conflicts of interest.

\section{REFERENCES}

1. Siegel RL, Miller KD, Jemal A. Cancer Statistics, 2017. CA Cancer J Clin. 2017; 67:7-30. https://doi.org/10.3322/ caac. 21387

2. Sanz-Garcia E, Grasselli J, Argiles G, Elez ME, Tabernero J. Current and advancing treatments for metastatic colorectal cancer. Expert Opin Biol Ther. 2016; 16:93-110. https://doi. org/10.1517/14712598.2016.1108405.
3. Fakih MG. Metastatic colorectal cancer: current state and future directions. J Clin Oncol. 2015; 33:1809-24. https:// doi.org/10.1200/JCO.2014.59.7633.

4. Spreadborough P, Doran C. The current thinking on colorectal cancer. J R Nav Med Serv. 2015; 101:47-54.

5. Tinholt M, Sandset PM, Iversen N. Polymorphisms of the coagulation system and risk of cancer. Thromb Res. 2016; 140:S49-54. https://doi.org/10.1016/S00493848(16)30098-6.

6. Swier N, Versteeg HH. Reciprocal links between venous thromboembolism, coagulation factors and ovarian cancer progression. Thromb Res. 2017; 150:8-18. https://doi. org/10.1016/j.thromres.2016.12.002.

7. Falanga A, Marchetti M, Vignoli A. Coagulation and cancer: biological and clinical aspects. J Thromb Haemost. 2013; 11:223-33. https://doi.org/10.1111/jth.12075.

8. Khorana AA. Cancer and coagulation. Am J Hematol. 2012; 87:S82-7. https://doi.org/10.1002/ajh.23143.

9. Soomro AY, Guerchicoff A, Nichols DJ, Suleman J, Dangas GD. The current role and future prospects of D-dimer biomarker. Eur Heart J Cardiovasc Pharmacother. 2016; 2:175-84. https://doi.org/10.1093/ehjcvp/pvv039.

10. Motavaf E, Sunesen KG, Stender MT, ThorlaciusUssing O. Prognostic value of preoperative D-dimer and carcinoembryonic antigen levels in patients undergoing intended curative resection for colorectal cancer: a prospective cohort study. Int J Colorectal Dis. 2014; 29:1427-32. https://doi.org/10.1007/s00384-014-2000-1.

11. Kilic M, Yoldas O, Keskek M, Ertan T, Tez M, Gocmen E, Koc M. Prognostic value of plasma D-dimer levels in patients with colorectal cancer. Colorectal Dis. 2008; 10:238-41. https://doi.org/10.1111/j.1463-1318.2007.01374.x.

12. Hong T, Shen D, Chen X, Wu X, Hua D. Preoperative plasma fibrinogen, but not D-dimer might represent a prognostic factor in non-metastatic colorectal cancer: A prospective cohort study. Cancer Biomark. 2017; 19:10311. https://doi.org/10.3233/CBM-160510.

13. Pedrazzani C, Cerullo G, Marrelli D, Fernandes E, Carlucci F, Corso G, Bettarini F, De Stefano A, Roviello F. Is circulating D-dimer level a better prognostic indicator than CEA in resectable colorectal cancer? Our experience on 199 cases. Int J Biol Markers. 2010; 25:171-6.

14. Wang JF, Guo Z, Tang L, Guo JS, Hu J, Liu JZ. [Prognostic associations of preoperative plasma levels of fibrinogen and D-dimer after curative resection in patients with colorectal cancer]. [Article in Chinese]. Zhonghua Yi Xue Za Zhi. 2013; 93:906-9.

15. Tekesin K, Bayrak S, Esatoglu V, Ozdemir E, Ozel L, Melih Kara V. D-Dimer and Carcinoembryonic Antigen Levels: Useful Indicators for Predicting the Tumor Stage and Postoperative Survival. Gastroenterol Res Pract. 2016; 2016:4295029. https://doi.org/10.1155/2016/4295029.

16. Blackwell K, Hurwitz H, Lieberman G, Novotny W, Snyder S, Dewhirst M, Greenberg C. Circulating D-dimer levels are 
better predictors of overall survival and disease progression than carcinoembryonic antigen levels in patients with metastatic colorectal carcinoma. Cancer. 2004; 101:77-82. https://doi.org/10.1002/cncr.20336.

17. Yamamoto $M$, Yoshinaga $K$, Matsuyama A, Iwasa $T$, Osoegawa A, Tsujita E, Yamashita Y, Tsutsui S, Ishida T. Plasma D-dimer level as a mortality predictor in patients with advanced or recurrent colorectal cancer. Oncology. 2012; 83:10-5. https://doi.org/10.1159/000338329.

18. Tellioglu G, Agcaoglu O, Siperstein A, Berber E. Serum D-dimer as a prognostic marker in patients undergoing radiofrequency ablation of colorectal liver metastasis. J Invest Surg. 2012; 25:295-300. https://doi.org/10.3109/08 941939.2011.642067.

19. Oya M, Akiyama Y, Okuyama T, Ishikawa H. High preoperative plasma D-dimer level is associated with advanced tumor stage and short survival after curative resection in patients with colorectal cancer. Jpn J Clin Oncol. 2001; 31:388-94.

20. Zhu L, Liu B, Zhao Y, Liu L, Yang C, Yang Y, Zhong H. High levels of D-dimer correlated with disease status and poor prognosis of inoperable metastatic colorectal cancer patients treated with bevacizumab. J Cancer Res Ther. 2014; 10:246-51. https://doi.org/10.4103/0973-1482.151451.

21. Zhao SXQ. The prognosis of D-dimer level in advanced colorectal cancer patients. Modern Oncology. 2016; 24:3953-6.

22. Xu HW, Xiang SS, Wu J. The relationships between preoperative D-dimer and prognosis of colorectal cancer. The Psychologist. 2015; 21:25-6.

23. Xue LN, He JL, Dong L, Cai Z, Zhang C. Correlation of plasma D-dimer level with the prognosis of the patients with metastatic and recurrent colorectal cancer. Journal of Chinese Practical Diagnosis and Therapy. 2011; 28:254-8.

24. Lee S, Huh SJ, Oh SY, Koh MS, Kim SH, Lee JH, Han JY, Choi HJ, Kim SJ, Kim HJ. Clinical significance of coagulation factors in operable colorectal cancer. Oncol Lett. 2017; 13:4669-74. https://doi.org/10.3892/ ol.2017.6058.

25. Chen W, Zheng R, Baade PD, Zhang S, Zeng H, Bray F, Jemal A, Yu XQ, He J. Cancer statistics in China, 2015. CA Cancer J Clin. 2016; 66:115-32. https://doi.org/10.3322/ caac. 21338 .

26. Brody H. Colorectal cancer. Nature. 2015; 521:S1. https:// doi.org/10.1038/521S1a.

27. Ge LP, Li J, Bao QL, Chen P, Jiang Q, Zhu LR. Prognostic and predictive value of plasma D-dimer in advanced non-small cell lung cancer patients undergoing first-line chemotherapy. Clin Transl Oncol. 2015; 17:57-64. https:// doi.org/10.1007/s12094-014-1198-2.
28. Go SI, Lee MJ, Lee WS, Choi HJ, Lee US, Kim RB, Kang MH, Kim HG, Lee GW, Kang JH, Lee JH, Kim SJ. D-Dimer Can Serve as a Prognostic and Predictive Biomarker for Metastatic Gastric Cancer Treated by Chemotherapy. Medicine (Baltimore). 2015; 94:e951. https://doi.org/10.1097/MD.0000000000000951.

29. Kilic L, Yildiz I, Sen FK, Erdem MG, Serilmez M, Keskin S, Ciftci R, Karabulut S, Ordu C, Duranyildiz D, Tas F. D-dimer and international normalized ratio (INR) are correlated with tumor markers and disease stage in colorectal cancer patients. Cancer Biomark. 2015; 15:40511. https://doi.org/10.3233/CBM-150477.

30. Ma X, Li Y, Zhang J, Huang J, Liu L. Prognostic role of D-dimer in patients with lung cancer: a meta-analysis. Tumour Biol. 2014; 35:2103-9. https://doi.org/10.1007/ s13277-013-1279-9.

31. Vossen CY, Hoffmeister M, Chang-Claude JC, Rosendaal $\mathrm{FR}$, Brenner H. Clotting factor gene polymorphisms and colorectal cancer risk. J Clin Oncol. 2011; 29:1722-7. https://doi.org/10.1200/JCO.2010.31.8873.

32. Yu JL, May L, Lhotak V, Shahrzad S, Shirasawa S, Weitz JI, Coomber BL, Mackman N, Rak JW. Oncogenic events regulate tissue factor expression in colorectal cancer cells: implications for tumor progression and angiogenesis. Blood. 2005; 105:1734-41. https://doi.org/10.1182/ blood-2004-05-2042.

33. Xu G, Zhang YL, Huang W. Relationship between plasma D-dimer levels and clinicopathologic parameters in resectable colorectal cancer patients. World J Gastroenterol. 2004; 10:922-3.

34. Mytnik M, Stasko J. D-dimer, plasminogen activator inhibitor-1, prothrombin fragments and protein $\mathrm{C}$ - role in prothrombotic state of colorectal cancer. Neoplasma. 2011; 58:235-8.

35. Inanc M, Er O, Karaca H, Berk V, Ozkan M, Dikilitas M, Elmali F. D-dimer is a marker of response to chemotherapy in patients with metastatic colorectal cancer. J BUON. 2013; 18:391-7.

36. Yu J, Li D, Lei D, Yuan F, Pei F, Zhang H, Yu A, Wang K, Chen H, Chen L, Wu X, Tong X, Wang Y. Tumor-Specific D-Dimer Concentration Ranges and Influencing Factors: A Cross-Sectional Study. PLoS One. 2016; 11:e0165390. https://doi.org/10.1371/journal.pone.0165390.

37. Stang A. Critical evaluation of the Newcastle-Ottawa scale for the assessment of the quality of nonrandomized studies in meta-analyses. Eur J Epidemiol. 2010; 25:603-5. https:// doi.org/10.1007/s10654-010-9491-z.

38. Ioannidis JP, Patsopoulos NA, Evangelou E. Uncertainty in heterogeneity estimates in meta-analyses. BMJ. 2007; 335:914-6. https://doi.org/10.1136/bmj.39343.408449.80. 